\title{
The role of high-dose chemotherapy in the treatment of testicular cancer
}

\author{
This article was published in the following Dove Press journal: \\ Open Access Journal of Urology \\ 12 February 2010 \\ Number of times this article has been viewed
}

\section{Alexandra Karadimou Meletios A Dimopoulos Aristotle Bamias \\ Dept of Clinical Therapeutics, University of Athens Medical School, Athens, Greece}

\begin{abstract}
Testicular cancer is a highly curable neoplasm, even in the case of extragonadal disease. Nevertheless, patients with adverse prognostic features or relapsing after first-line cisplatin-based chemotherapy have a worse prognosis with a death rate greater than $50 \%$. Highdose chemotherapy (HDC) has long been used in this group of patients. The introduction of stem cells, instead of bone marrow, as the source of hemopoietic cells and the use of leukocyte growth factors have substantially reduced the mortality and morbidity of this procedure although the role of HDC is not well defined. This review summarizes the available data, focusing on published randomized studies. The problems associated with the design of these studies and the interpretation of data are discussed. Currently this HDC approach is mainly used in patients who relapse after first-line chemotherapy. Nevertheless, selection of patients likely to benefit from this treatment remains an issue of intense clinical research.
\end{abstract}

Keywords: high-dose chemotherapy, testicular cancer, salvage therapy

\section{Introduction}

\section{High-dose chemotherapy}

The antitumor effect of chemotherapeutic agents appears to be dose-dependent, at least in chemosensitive neoplasms. It is therefore reasonable to believe that "more is better" and that superior results can be achieved if chemotherapy is administered at doses significantly higher than those conventionally used. This has created the concept of high-dose chemotherapy, which has been used with success in certain hematological malignancies although its application is more limited in solid tumors.

The action of cytotoxic agents is nonspecific and this eventually results in adverse events in normal tissues. One of the most serious and potentially life-threatening toxicities is myelosuppression, which also represents the dose-limiting toxicity of many chemotherapeutic agents. This can be theoretically overcome by the transplantation of bone marrow hematopoietic cells, which by engraftment to the bone marrow of the patient will restore hemopoiesis and immunity. When the graft is taken from the patient's own bone marrow the procedure is called autologous. Autologous transplant has the advantage that it does not require histocompatibility matching and has no risk of rejection or graft versus host disease (GVHD) and consequently no need for immunosuppressive therapy. However, autologous transplants may be contaminated with malignant cells and do not confer a graft versus malignancy (GVM) effect.

The availability of hemopoietic growth factors led to the use of peripheral blood stem (or progenitor) cells (PSC) instead of bone marrow for autologous hemopoietic stem cell
Correspondence: Aristotle Bamias Oncology Unit, Alexandra Hospital, 80 Vas, Sofias Avenue, II 528 Athens, Greece

Tel +30210338 I546

$\mathrm{Fax}+302103381511$

Email abamias@med.voa.gr 
transplantation(HSCT). ' The use of these cells after 'mobilization' using granulocyte-colony stimulating factors (G-CSF) resulted in reduced morbidity and mortality because they engraft more rapidly, thus shortening the period of pancytopenia. In addition they have a greater chance of therapy success, as they have a lower frequency of tumor cell contamination, compared to grafts taken from the patient's bone marrow and apparently do not need purging methods. Therefore the procedure became easier and more applicable even by less specialized and nonacademic centers. These cells are kept by cryopreservation and may be infused back into the patient following a time interval dependent upon the half-life of the agents used for high-dose chemotherapy. Patients subsequently receive high-dose myelosuppressive therapy to eradicate any residual disease.

\section{Testicular cancer}

Testicular cancer represents a model of curable solid tumor since most patients will be cured irrespective of the tumor stage initially diagnosed. This unusually favorable outcome, (for solid tumors), is achieved by the high sensitivity of this tumor to cisplatin-based chemotherapy.

The prognosis of testicular tumors not confined to the testis (stages II and III) is defined by the International Germ Cell Cancer Cooperative Group (IGCCCG) criteria, which are based on the histological type (seminoma vs nonseminoma), the primary site, sites of metastases and prechemotherapy alpha-fetoprotein $(\alpha \mathrm{FP})$, beta human chorionic gonadotropin (bhCG) and lactate dehydrogenase (LDH) (Table 1). ${ }^{2}$ The combination of bleomycin, etoposide and cisplatin (BEP) represents the standard of care for these patients. Nevertheless, the outcome for patients, at high-risk for relapse, is not satisfactory, with a cure rate lower than $50 \%$ with $\mathrm{BEP}^{3}$ Patients who relapse after first-line chemotherapy represent another group with an unfavorable prognosis. The cure rate within this group is approximately $25 \%$ with conventional chemotherapy. ${ }^{4}$ These two groups clearly represent a group of patients who might benefit from more intensive chemotherapy, including high-dose chemotherapy (HDC).

Table I IGCCCG risk classification for advanced testicular cancer

\begin{tabular}{|c|c|c|}
\hline & Seminoma & Non-seminoma \\
\hline \multirow[t]{6}{*}{ Good risk } & All of the following: & All of the following: \\
\hline & Any bhCG & bhCG $<5000 \mathrm{mlu} / \mathrm{mL}$ \\
\hline & Any LDH & $\alpha \mathrm{FP}<1000 \mathrm{ng} / \mathrm{mL}$ \\
\hline & & $\mathrm{LDH}<\mathrm{I} .5 \times \mathrm{ULN}$ \\
\hline & No nonpulmonary visceral metastases & No nonpulmonary visceral metastases \\
\hline & Any primary site & Gonadal or retroperitoneal primary \\
\hline \multirow[t]{7}{*}{ Intermediate risk } & Any bhCG & Any of the following: \\
\hline & Any LDH & $\alpha \mathrm{FP} 1000-10,000 \mathrm{ng} / \mathrm{mL}$ \\
\hline & & bhCG 5000-50,000 mlu/mL \\
\hline & & LDH I.5-10.0 ULN \\
\hline & Nonpulmonary visceral metastases & AND \\
\hline & Any primary site & No nonpulmonary visceral metastases \\
\hline & & Gonadal or retroperitoneal primary site \\
\hline \multirow[t]{9}{*}{ Poor risk } & Nonapplicable & Mediastinal primary site \\
\hline & & OR \\
\hline & & Nonpulmonary visceral metastases \\
\hline & & OR \\
\hline & & $\alpha F P \geq 10,000 \mathrm{ng} / \mathrm{mL}$ \\
\hline & & OR \\
\hline & & $\mathrm{bhCG} \geq 50,000 \mathrm{mlu} / \mathrm{mL}$ \\
\hline & & OR \\
\hline & & $\mathrm{LDH} \geq 10 \times \mathrm{ULN}$ \\
\hline
\end{tabular}

Abbreviations: IGCCCG, International Germ Cell Cancer Cooperative Group; $\alpha$ FP, fetoprotein; bhCG, beta human chorionic gonadotropin; LDH, lactate dehydrogenase; ULN, upper limit of normal. 
Several nonrandomized studies of intensified chemotherapy as consolidation or salvage treatment have suggested a benefit for poor risk patients when compared to what has been achieved historically. ${ }^{5-7}$ Such results have provided the theoretical background for the use of HDC in testicular cancer. HDC initially with autologous bone marrow and then with HSCT has been used for nearly two decades and has shown high response rates and promising disease-free rates in poor risk patients (prior to the establishment of the IGCCCG criteria) in predominantly noncontrolled trials. ${ }^{8}$ These results provided the theoretical basis to explore the role of this approach in the randomized studies, which are reviewed below.

\section{High risk, first-line chemotherapy}

The feasibility of HDC, in the first-line setting, in poor risk patients has been established in several phase II studies. ${ }^{9-11}$ The results of some of these have suggested that the use of this modality may improve the pathological outcome for these patients. Nevertheless, data from randomized studies is limited.

Two randomized studies that included 115 and 219 patients failed to show any benefit from using HDC in this group (Table 2). ${ }^{12,13}$ In these two studies patients were randomized to receive two cycles of conventional chemotherapy and then continue with this chemotherapy or 1 or 2 cycles of HDC. The first study used autologous bone marrow to support patients after HDC. The substitution of bone marrow for stem cells resulted in a more rapid engraftment which permitted a second course of HDC with fewer delays. This strategy was applied in the second study. Conventional chemotherapy consisted of etoposide, bleomycin, vinblastine, and cisplatin (PVeBV) or the current standard BEP. Both studies included intermediate and poor-risk patients and used high-dose cyclophosphamide and etoposide, while double the dose of cisplatin or high-dose carboplatin were the other drugs used, respectively. Toxicity was considerable, with $5 \%$ of patients dying due to the toxicity of the chemotherapy regimen in both studies, with more (although not all) in the high-dose arms. However, a more recent study, reported in abstract form, failed to show any benefit from the administration of HDC. ${ }^{14}$ This study did not complete accrual, a common problem of studies using HDC in a first-line setting.

Although current evidence does not support the use of HDC in a first-line setting, there are several reasons which might account for the negative results, apart from a lack of superiority of HDC over the current standard chemotherapy regimens: insufficient number of patients to detect a realistic difference in survival; suboptimal HDC (ie, use of cyclophosphamide at the expense of lower doses of the more active drugs) and a substantial number of patients who did not receive HDC being the most important. The first study also suffered from the fact that the cisplatin total dose and dose intensity were lower in the HDC arm compared to that of conventional chemotherapy.

In addition to the published randomized studies, Bokemeyer performed a matched pair analysis to assess the benefit from HDC in a first-line setting. ${ }^{15} \mathrm{He}$ compared the outcome of 146 patients who had received high-dose platinum, etoposide and ifosfamide with that of 309 matched patients who had received conventional chemotherapy. Patients were stratified according to the IGCCCG risk criteria. There was a $81 \% 3$-year overall survival (OS) rate with HDC as compared to $61 \%$ with conventional doses $(P=0.018)$. Failure during first-line therapy predicted for no benefit from HDC.

In spite of the above limitations valuable information was derived from the two randomized studies as well as other allied studies, particularly regarding subsets of patients who might benefit from this approach. Patients with unsatisfactory marker decline have long been identified as having a poorer prognosis than those with a decline according to the

Table 2 Randomized studies of high-dose chemotherapy as first-line treatment for germ cell tumours

\begin{tabular}{|c|c|c|c|c|c|c|}
\hline References & $\begin{array}{l}\text { Conventional } \\
\text { chemotherapy }\end{array}$ & HDC regime & Pts & Support & os & $P$ \\
\hline \multirow[t]{4}{*}{12} & $\mathrm{PVeBV} \times 3-4$ & Eto 1750 & 115 & ABMT & 5-year & 0.167 \\
\hline & & Cyclo 8400 & & & 75\% (PVeBV) & \\
\hline & & CDDP 200 & & & $61 \%(H D C)$ & \\
\hline & & XI & & & & \\
\hline \multirow[t]{3}{*}{13} & BEPx4 & Carbo 1800 & 219 & $\mathrm{HSCT}$ & 2-year & 0.94 \\
\hline & & Eto 600 & & & 72\% (BEP) & \\
\hline & & Cyclo 150 & & & $71 \%(\mathrm{HDC})$ & \\
\hline
\end{tabular}

Abbreviations: PVeBV, cisplatin, vinblastine, bleomycin, etoposide; BEP, bleomycin, etoposide, cisplatin; HDC, high-dose chemotherapy;ABMT, autologous bone marrow transplantation; HSCT, hemopoietic stem cell transplantation. 
expected half-life of $\alpha \mathrm{FP}$ and bhCG. ${ }^{16-18}$ Subgroup analysis in one of the randomized studies indicated that these patients might benefit from more intensive therapy, such as HDC. ${ }^{13}$ An individualized approach based on marker decline and including HDC for patients with unsatisfactory decline, in spite of initial intensification with the addition of ifosfamide to BEP, has been recently reported in abstract form. ${ }^{19}$ Encouraging results, especially for the intermediate risk group, were observed. Nevertheless, until prospective validation of these findings, this approach should still be considered investigational and the best management of these patients is their inclusion in ongoing prospective studies.

\section{Salvage treatment in patients in progressing or relapsing after first-line chemotherapy}

The prognosis of patients relapsing after or progressing on first-line chemotherapy is not favorable. These patients can be treated with cisplatin-based chemotherapy. Etoposide and bleomycin are typically substituted for vinblastine, ifosfamide or more recently paclitaxel. ${ }^{20-22}$ No convincing evidence regarding the superiority of any salvage regimen over the others currently exist, it is generally accepted that relapsing patients represent a prognostically heterogeneous group with a long-term remission rate ranging from $15 \%$ to $60 \%$. Several prospective studies and retrospective analyses have identified several prognostic factors which are shown in Table $3 .{ }^{3}$ Relapsing patients represent the group where HDC has been widely accepted as an option, although strong evidence from randomized studies and uniform consensus are still lacking.

In the study by Pico and colleagues 280 patients were randomized to receive 4 cycles of ifosfamide, cisplatin and etoposide (VIP) or vinblastine (VeIP) versus 3 cycles plus one cycle of HDC (carboplatin/etoposide/cyclophosphamide) with $\mathrm{HSCT}^{23}$ No survival benefit was detected, although

Table 3 Factors associated with prognosis in patients with germ cell tumors relapsing after or progressing on first-line chemotherapy

\begin{tabular}{ll}
\hline Good prognosis & Poor prognosis \\
\hline Seminoma & Non-seminoma \\
Gonadal & Extragonadal \\
CR/marker -ve PR in first-line & Marker +ve PR/SD/PD in first-line \\
Nodal/pulmonary metastases & Extrapulamonary metastases \\
$\alpha$ FP $<1000$ & $\alpha F P \geq 1000$ \\
bhCG $<1000$ & bhCG $\geq 1000$ \\
\hline
\end{tabular}

Abbreviations: $\alpha F P$, fetoprotein; bhCG, beta human chorionic gonadotropin; $\mathrm{CR}$, complete response; PR, partial response; SD, stable disease; PD, progressive disease. the trial was not powered to detect smaller differences. The number of patients that died due to toxicity during conventional chemotherapy and HDC, was 3\% and 7\% respectively. Most patients included in this study had good prognostic features. Therefore, these patients should be treated with conventional salvage chemotherapy and not HDC.

In patients with poor prognostic features, several phase II studies suggested that HDC may increase the chances for long-term disease-free survival (DFS) when compared to historical controls. ${ }^{24-26} \mathrm{~A}$ retrospective analysis of patients who received or did not receive one cycle of HDC at first relapse was performed by the German and British Medical Research Council (MRC) group. ${ }^{27}$ Patients in the two groups were matched for five (38 pairs) or for four (17 pairs) prognostic factors. There was a suggestion of benefit from HDC with an estimated absolute improvement in 2-year event-free survival of $6 \%-12 \%$ (hazard ratio [HR] $0.72-0.84$ ) and an OS 9\%-11\% (HR 0.77-0.83). Nevertheless, such an analysis is no substitute for a benefit shown in the context of a randomized trial.

Several phase II studies using HDC at second or subsequent relapses have been reported. ${ }^{28-34}$ This area represents the most widely studied application of high-dose chemotherapy. The various studies including more than 40 patients and reported in a full paper form are outlined in Table 4. Carboplatin, etoposide, cyclophosphamide and ifosfamide have been the most popular drugs used in HDC. Paclitaxel, an agent with established activity in germ cell tumors has also been recently used in HDC in two phase II studies. ${ }^{32-34}$ These studies have included small numbers of patients but they have both shown the feasibility of this treatment.

Undoubtedly, HDC represents a curative option for a significant percentage of patients with more than one relapse of germ cell tumors. Postchemotherapy resection of residual tumor still represents an integral component of a successful approach for these patients. ${ }^{35}$

\section{Outcome after HDC in germ cell tumors}

The results discussed above have established high-dose chemotherapy as an effective option in poor prognosis patients in first relapse as well as in patients beyond first relapse. Nevertheless, certain issues, such as the considerable toxicity (including deaths) as well as the fact that such an approach can only be offered in selected, experienced centers, make the careful selection of patients likely to benefit from this treatment of paramount importance. In spite of the lack of randomized studies in this setting, the existing data have established certain factors, which might aid patients' selection. 
Table 4 HDC with HSCT in more than one relapses of germ cell tumors

\begin{tabular}{|c|c|c|c|c|c|c|c|c|}
\hline References & Carboplatin & CPM & ETO & IFO & Pts & $\begin{array}{l}\text { Number } \\
\text { of cycles }\end{array}$ & CR & $\begin{array}{l}\text { NED/median } \\
\text { follow-up }\end{array}$ \\
\hline 27 & 1500 & 60 & 1200 & & 58 & $\mathrm{I}-2$ & $40 \%$ & $21 \% / 28 \operatorname{mos}$ \\
\hline 28 & & & & & 47 & $\mathrm{I}-2$ & $49 \%$ & $43 \% / 33$ mos \\
\hline 29 & 1350 & & 1800 & & 84 & $\mathrm{I}-2$ & & $33 \% /$ \\
\hline 30 & $1500-2000$ & & $1200-2400$ & $0-10$ & 150 & I & & $29 \% /$ \\
\hline
\end{tabular}

Abbreviations: CPM, cyclophosphamide; ETO, etoposide; IFO, ifosfamide; CR, complete response; NED, no evidence of disease.

The first study to establish prognostic factors regarding the outcome after HDC in 310 patients with relapsed germ cell tumors was reported by Beyer and colleagues in $1996 .{ }^{36}$ These patients had received conventional VIP or VeIP followed by one course of HDC. Eighty-five percent of patients had received at least two previous regimens. Four adverse prognostic factors were identified, refractory disease consequent to first-line treatment (relapse within 4 weeks), absolute refractory disease (no response to initial chemotherapy), mediastinal primary and a serum bhCG of $\geq 1000$ $\mathrm{IU} / \mathrm{L}$. Based on the score assigned to each of these factors a model of three prognostic groups was developed, low risk (no adverse feature), intermediate and poor. The rate of disease-free survival at 2 years was only $5 \%$ for a score of 3 or higher compared to $51 \%$ for those with a score of 0 . Indiana University has also reported their own experience in 80 , less heavily pre-treated, patients (only $46 \%$ had received two prior regimes).$^{37}$ Treatment consisted of VIP/VeIP followed by tandem ( 2 courses) HDC. The Beyer model was partially confirmed; since patients with Beyer score $>2$ had a significantly worse outcome. Other adverse prognostic factors were: absolute refractory disease (no response to initial chemotherapy), mediastinal primary, a serum bhCG of $\geq 1000 \mathrm{IU} / \mathrm{L}$ or $\alpha \mathrm{FP} \geq 1000 \mathrm{ng} / \mathrm{ml}$.

A more recent analysis of 184 consecutive patients at Indiana University ${ }^{38}$ confirmed the value of some of these factors, although the final model included only platinumrefractory disease, while the use of HDC later than the first relapse and initial IGCCCG high-risk stage, were the other two adverse prognostic features. The overall results were better than those reported by Beyer, with $63 \%$ of patients being disease-free after a median follow up of 4 years. Most of these patients $(90 \%)$ had been followed up for a minimum of 2 years. The superior results of Einhorn and colleagues may be attributed to several factors; earlier use of HDC, administration of two rather than one cycles of HDC and the omission of cyclophosphamide from the high-dose regimen, thus allowing for higher doses of the two most active drugs etoposide and carboplatin. There are two important points to be taken by this more recent study, a) HDC should be used in the first relapse if possible, and b) long term disease-free survival was achieved across all categories of patients, even those with unfavorable characteristics according to Table 3. Therefore, HDC may represent the best option for patients in first relapse and unfavorable prognosis.

\section{Conclusion}

HDC with autologous HSCT represents an option for relapsed patients with germ cell tumors, especially those with poor prognosis if they were treated with conventional salvage chemotherapy. The advances in the collection of stem cells and support during the period of myelosuppression have made this therapy safe and applicable to most patients. Nevertheless, there are several questions to be answered, such as the number of cycles of HDC and the agents to be used. More importantly, the patients who will clearly benefit from this treatment have not been clearly identified and more research in this field is warranted.

\section{Disclosures}

The authors report no conflicts of interest in this work.

\section{References}

1. Flechon A, Culine S, Droz JP. Intensive and timely chemotherapy, the key of success in testicular cancer. Crit Rev Oncol Haematol. 2001;37:35-46.

2. International Germ Cell Cancer Consensus Group. International Germ Cell Consensus Classification: a prognostic factor-based staging system for metastatic germ cell cancers. J Clin Oncol. 1997;15:594-603.

3. Krege S, Beyer J, Souchon R, et al; European Consensus Conference on diagnosis and treatment of germ cell cancer: a report of the Second Meeting of the European Germ Cell Cancer Consensus Group (EGCCCG): part II. Eur Urol. 2008;53:497-513.

4. Loehler PJ, Godin R, Nichols CR, et al. Vinblastine plus ifosfamide plus cisplatin as initial salvage therapy in recurrent germ cell tumor. J Clin Oncol. 1998;16:2500-2504.

5. Bokemeyer C, Harstrick A, Beyer J, et al. The use of dose-intensified chemotherapy in the treatment of metastatic nonseminomatous testicular germ-cell tumors. Semin Oncol. 1998;25:24-32.

6. Horwich A, Dearnaley DP, Norman A, Nicholls J, Hendry WF. Accelerated chemotherapy for poor prognosis germ-cell tumors. Eur J Cancer. 1994;11:1607-1611. 
7. Feldman DR, Bosl G, Sheinfeld J. Medical treatment of advanced testicular cancer. JAMA. 2008;299:672-684.

8. Droz JP, Pico JL, Ghosn M, et al. A phase Ii trial of early intensive chemotherapy with autologous bone marrow transplantation in the treatment of poor prognosis non-seminomatous germ-cell tumors. Bull Cancer. 1992;79:497-507.

9. Motzer RJ, Mazudmar M, Lyn P, et al. High-dose carboplatin, etoposide and cyclophosphamide in first-line therapy for poor-risk germ cell tumors. J Clin Oncol. 1996;14:2546-2552.

10. Decatris MP, Wilkinson PM, Welch RS, et al. High-dose chemotherapy with autologous hematopoietic support in poor-risk nonseminomatous germ cell tumors: an effective first-line therapy with minimal toxicity. Ann Oncol. 2000;11:427-434.

11. Schmoll HJ, Kollmannsberger C, Metzner B, et al; Long-term results of first-line sequential high-dose etoposide, ifosfamide and cisplatin chemotherapy plus autologous stem-cell support for patients with advanced metastatic germ cell cancer: an extended phase I/II study of the German Testicular Cancer Study Group. J Clin Oncol. 2003;21:4083-4091.

12. Droz JP, Kramar A, Biron P, et al. Failure of high-dose cyclophosphamide and etoposide combined with double-dose cisplatin and bone marrow support in patients with high-volume metastatic nonseminomatous germ cell tumors: mature results of a randomized trial. Eur $J$ Urol. 2007;51:739-748.

13. Motzer RJ, Nichols CJ, Margolin KA, et al. Phase III randomized trial of conventional-dose chemotherapy with or without high-dose chemotherapy and autologous hematopoietic stem-cell rescue as first-line treatment for patients with poor-prognosis metastatic germ cell tumors. J Clin Oncol. 2007;25:247-256.

14. Di Nicola M, Necchi A, Nicolai N, et al. High-dose sequential chemotherapy versus conventional-dose chemotherapy as first-line treatment in advanced poor prognosis germ cell tumors: a multicenter phase III Italian study. Eur J Cancer. 2009;7(Suppl 2):422.

15. Bokemeyer C, Kollmannsberger C, Meisner C, et al. First-line high-dose chemotherapy compared with standard-dose PEB/VIP chemotherapy in patients with advanced germ cell tumors: a multivariate and matched pair analysis. J Clin Oncol. 1999;17:3450-3456.

16. Mazudmar M, Bajorin DF, Bacik J, et al. Predicting outcome to chemotherapy in patients with germ cell tumors: the value of the rate of decline of human chorionic gonadotropin and alpha-fetoprotein during therapy. J Clin Oncol. 2001;19:2534-2541.

17. Fizazi K, Culine S, Kramar A, et al. Early predicted time to normalization of tumor markers predicts outcome in poor-prognosis nonseminomatous tumors. J Clin Oncol. 2004;22:3868-3871.

18. Murphy BA, Motzer RJ, Mazudmar M, et al. Serum tumor marker decline is an early predictor of treatment outcome in germ cell tumor patients treated with cisplatin and ifosfamide salvage therapy. Cancer. 1994; 73:2520-2526.

19. Oloffson S, Dahl O, Jerkeman M, et al. Individualized intensification of treatment based on tumor marker decline in metastatic nonseminomatous germ cell testicular cancer (NSGCT): a report from the Swedish Norwegian Testicular Cancer Group SWENOTECA. J Clin Oncol. 2009;27:15s.

20. Loehler PJ, Gonin R, Nichols CR, et al. Vinblastine plus ifosfamide plus cisplatin as initial salvage therapy in recurrent germ cell tumor. J Clin Oncol. 1998;13:1170-1176.

21. McCaffrey JA, Mazudmdar M, Bajorin DF, et al. Ifosfamide- and cisplatin-containing chemotherapy as first-line salvage therapy in germ cell tumor: response and survival. J Clin Oncol. 1997;15:2559-2554.
22. Sonpavde G, Hutson TE, Roth BJ. Management of recurrent testicular germ cell tumors. The Oncologist. 2007;12:51-61.

23. Pico JL, Rosti G, Kramar A, et al. A randomized trial of high-dose chemotherapy in the salvage treatment of patients failing first-line platinum chemotherapy for advanced germ cell tumors. Ann Oncol. 2005;16:1152-1159.

24. Broun ER, Nichols CR, Gize CK, Hromas K, Schacht B, Einhorn LH. Tandem high-dose chemotherapy with autologous bone marrow transplantation for initial relapse of testicular germ-cell cancer. Cancer. 1997;79:1605-1610.

25. Horwich A, Wilson C, Cornes P, Gildersleve J, Dearnaley D. Increasing the dose-intensity of chemotherapy in poor-prognosis metastatic nonseminoma. Eur Urol. 1993;23:219-222.

26. Flechon A, Biron P, Droz JP. High-dose chemotherapy with haematopoietic stem cell support in germ cell tumor patient treatment: the French experience. Int J Cancer. 1999;83:844-847.

27. Beyer J, Stenning S, Gerl A, et al. High-dose versus conventional dose chemotherapy as first-salvage treatment in patients with nonseminomatous germ-cell tumors: a matched pair analysis. Ann Oncol. 2002;13:599-605.

28. Motzer RJ, Mazudmar M, Bosl GJ, et al. High-dose carboplatin, etoposide and cyclophosphamide for patients with refractory germ-cell tumors: treatemnt results and ptognostic factors for survival anf toxicity. J Clin Oncol. 1996;14:1098-1105.

29. Motzer RJ, Mazumdar M, Sheinfeld J, et al. Sequential dose-intensive paclitaxel, ifosfamide, carboplatin, and etoposide salvage therapy for germ cell tumor patients. J Clin Oncol. 2000;18:1173-1180.

30. Rosti G, De Giorgi U, Salvioni R, et al. Salvage high-dose chemotherapy in patients with germ cell tumors: an Italian experience with 84 patients. Cancer. 2002;95:309-315.

31. Rick O, Beyer J, Kingreen D, et al. High-dose chemotherapy in germ cell tumours: a large single centre experience. Eur J Cancer. 1998;34:1883-1888.

32. McNeish IA, Kanfer EJ, Haynes R, et al. Paclitaxel-containing high-dose chemotherapy for relapsed or refractory testicular germ cell tumors. Br J Cancer. 2004;90:1169-1175.

33. Margolin KA, Doroshow JH, Frankel P, et al. Paclitaxel-based high-dose chemotherapy with autologous stem cell rescue fro relapsed germ cell cancer. Biol Bone Marrow Transplant. 2005;11:903-911.

34. Rick O, Beyer J, Hartmann JT, et al. Salvage treatment with paclitaxel, ifosfamide, and cisplatin plus high-dose carboplatin, etoposide, and thiotepa followed by autologous stem-cell rescue in patients with relapsed or refractory germ cell tumours. J Clin Oncol. 2001;19:81-88.

35. Rick O, Bokemeyer C, Weinknecht $\mathrm{S}$, et al. Residual tumor resection after high-dose chemotherapy in patients with relapsed or refractory germ cell cancer. J Clin Oncol. 2004;22:3713-3719.

36. Beyer J, Kramar A, Mandanas R, et al. High-dose chemotherapy as salvage treatment in germ cell tumors: a multivariate analysis of prognostic variables. J Clin Oncol. 1996;14:2638-2645.

37. Vaena DA, Abonour R, Einhorn LH, et al. Long-term survival after high-dose chemotherapy for germ cell malignancies with adverse prognostic variables. J Clin Oncol. 2003;21:4100-4104.

38. Einhorn LH, Williams SD, Chamness A, Brames MJ, Perkins SM, Abonour R. High-dose chemotherapy and stem-cell rescue for metastatic germ-cell tumors. N Engl J Med. 2007;357:340-348.
Open Access Journal of Urology

\section{Publish your work in this journal}

The Open Access Journal of Urology is an international, peer-reviewed, open access journal publishing original research, reports, editorials, reviews and commentaries on all aspects of adult and pediatric urology in the clinic and laboratory including the following topics: Pathology, pathophysiology of urological disease; Investigation and treatment of

\section{Dovepress}

urological disease; Pharmacology of drugs used for the treatment of urological disease. The manuscript management system is completely online and includes a very quick and fair peer-review system, which is all easy to use. Visit http://www.dovepress.com/testimonials.php to read real quotes from published authors. 